\title{
INTRODUCCIÓN CRÍTICA A LOS ORÍGENES Y FUNDAMENTOS TEÓRICOS DE LA ANTROPOLOGÍA AMBIENTAL O ECOLÓGICA. UNA CIENCIA CON MUCHO MANÁ Y CARGOS (CULT) POSOS
}

\section{Felipe Cárdenas 1}

Departamento de Ciencia Política y Derechos Humanos

Universidad de La Sabana (Colombia)

https://doi.org/_0.33676/EMUI_nomads.57.09

Resumen.- Con base en la determinación sintética de lecturas antropológicas, el artículo identificará algunos de los principales argumentos que han marcado el desarrollo de la antropología ecológica. Se hacen explícitos los principales hallazgos en función de la interacción compleja que acontece en el estudio de la relación ecosistema cultura como las antinomias intelectuales que han marcado el desarrollo de la disciplina y que hacen de ella una ciencia que, en su identidad, algunos pretenden como ligada a las ciencias naturales y otros a las humanidades.

Palabras clave: Antropología, cultura, historia de la antropología, ecosistema, naturaleza Critical introduction to the origins and theoretical foundations of environmental or ecological anthropology. A science with a lot of mana and charges (cult)

Abstract: A science with a lot of mana and cult (guilty) cargos. Critical introduction to the origins and theoretical foundations of environmental or ecological anthropology. The article will identify some of the main arguments that have marked the development of ecological anthropology based on the synthetic determination of anthropological readings. The main findings are made explicit in terms of the complex interaction that takes place in the study of the relationship ecosystem culture as the intellectual antinomies that have marked the development of the discipline, some claim as linked to the natural sciences and others to the humanities.

Keywords: Anthropology, culture, history of anthropology, ecosystem, nature

\section{INTRODUCCIÓN}

La historia de la antropología estará marcada por la presencia de variadas temáticas cuyos ejes de análisis, como identificará este trabajo, refieren acercamientos profundos y variados sobre el análisis de la interacción ecosistema-cultura. El propósito de este trabajo es dar cuenta

\footnotetext{
1 Felipe Cárdenas CV, unisabana.academia.edu/FelipeCárdenas/CurriculumVitae
} 
de los diversos paisajes intelectuales que estructuran la antropología en su aproximación al hecho humano y en concreto a las visiones teóricas que han acompañado a la antropología ambiental o ecológica. La frontera del conocimiento ambiental ha sido señalada como fructífera desde perspectivas naturalistas, sociales e incluso algunas fundamentadas en la antropología semiótica y que tendrán que seguir profundizándose (Véase Cárdenas, 2016). Para los antropólogos, el resultado sintético de sus abstracciones teóricas está en comprender que la cultura modela a la naturaleza y que ocurre lo mismo con la cultura, ya que ella está condicionada por factores biofísicos y ambientales. En ese sentido, numerosa información antropológica, producto de miles de descripciones etnográficas a lo largo del mundo y realizadas a lo largo de más de cien años, abren ventanas para observar las diversas relaciones que se establecen por parte de los sistemas culturales y las relaciones que dan con la base natural o ecosistémica del planeta. La complejidad de relaciones estudiadas y analizadas por los antropólogos, hoy alertan sobre los reduccionismos materialistas o simbólicos. Si bien en función de la modelación geoinformática, el reduccionismo científico se puede seguir presentando, lo cierto es que hoy ya no es el camino indicado para la indagación antropológica en referencia al núcleo del trabajo de investigación: la relación ecosistema-cultura, sociedad-naturaleza o biología-cultura.

Como se observará en el artículo, la cultura involucra varios componentes y propiedades. Los procesos mentales, creencias, conocimientos y valores son parte de la cultura. La conducta de todos los seres humanos está condicionada por un sistema de valores y creencias que le impone la tradición al individuo y que es aprendida por éste. Para la antropología ha sido muy importante el estudio de los modelos cognitivos de las culturas, entendidos como patrones de conocimiento propios que una cultura ha elaborado sobre la realidad. Prácticamente toda información antropológica, le guste o no le guste al hombrecito de la modernidad en su referencia a los modelos cognitivos de pueblos salvajes, primitivos o barbaros, es particularmente la expresión de lecturas y observaciones que refieren manifestaciones sobre ámbitos de lo que se denomina el hecho religioso o el subsistema de la religión. La cultura en su máximo apogeo o decadencia es cultura porque es culto, es decir mitologema actuado como mito y rito. Acá la evidencia no es sólo de la antropología cultural. Otras disciplinas y enfoques con los cuales la antropología ha dialogado, tales como la historia de las religiones, psicología, sociología, ontología, fenomenología religiosa, filosofía de la religión y teología complejizan las lecturas antropológicas que pretendan guiarse solamente de variables tecno-ambientales y tecno-económicas, como lo propone el modelo de Marvin Harris (1968), en su comprensión del hecho humano. 
Como consideración central al pensamiento de este trabajo de investigación teórica, se hace una defensa del concepto polivalente de cultura manejado por la antropología. A diferencia de lo que algunos antropólogos contemporáneos creen, el trabajo afirma que la categoría de cultura es uno de argumentos más poderosos con los que cuenta la disciplina. El concepto permite, por un lado, captar las dimensiones y categorías temáticas básicas para la comprensión de lo humano, tales como la organización social, religión, historia, conducta, valores, funciones, ideas, estructuras, símbolos, tecnologías y por otro lado, para comprender procesos económicos, políticos y sociales determinantes en la expresión de los problemas ambientales, que tienen a diferencia de lo que piensan los biólogos y ecólogos, características culturales más que simplemente condiciones antrópicas. Estas diferencias son fundamentales para comprender la importancia de la historia y la cultura en la génesis y posible mitigación de cambios ambientales derivados del universo cultural de las civilizaciones industrializadas de la modernidad.

\section{Nuestro problema: una ciencia con muchos problemas empíricos y teóricos aun no resueltos}

Se puede señalar que la antropología desde sus orígenes y dado su coqueteo con las ciencias naturales, piénsese en Edward Burnett Tylor (1832-1917), ha estado marcada como disciplina por obsesiones científicas cuya teleología naturalista y heurística ha buscado en sus extremos positivistas la realización de lecturas de procesos de descripción, comprensión e interpretación de la relación ecosistema-cultura o de los vínculos entre la biología y la cultura. Por una parte, podría decirse que nuestro mito fundacional inició con la definición dada por Tylor (1871) [1920] de la cultura:

... "La cultura o civilización, en sentido etnográfico complejo que incluye el conocimiento, las creencias. El arte, la moral, el derecho, las costumbres y cualesquiera otros hábitos y capacidades adquiridos por el hombre en cuanto miembro de la sociedad".

Por otra parte, la narratividad científica de la antropología cultural y social ha encontrado fuentes de inspiración en abordajes hermenéuticos e interpretativos, cuyas fuentes se recrean en los lenguajes de la filosofía existencialista de Heiddeger, en las construcciones esotéricas de Carlos Castaneda (1976, 1984) o en el "cientifismo" autoreferencial de Gregory Bateson, cuya obra densa tiene pocas referencias al trabajo de otros antropólogos y sus ideas (1993). 
Consecuentemente, uno de los principales rasgos que de entrada tenemos que tener presente para entender que el ser humano es un animal que se comporta de manera extraña si lo comparamos con otros animales, se refiere a sus esquemas innatos de comportamiento, que en palabras de un etólogo son muy rudimentarios (Lorenz, K citado por Pannenberg, 1993). El hombre genérico, se "autodomestica" por la vía de la cultura. jLa cultura es el nicho por excelencia del ser humano! Parece que el comportamiento humano no está totalmente limitado por su aparato pulsional e instintivo; su entorno no lo condiciona como en otros animales en términos de estímulo-respuesta. El entorno del ser humano no es solamente perceptivo sino, principalmente, simbólico. El ser humano es un símbolo. Es decir, un signo cualificado y complejo, que no se puede entender de manera directa, que tiene la capacidad de proyectar su sistema nervioso central fuera de sí mismo, extrasomatizando los procesos de la realidad y generando formas materiales con vida propia que terminan condicionando la conciencia humana y determinando necesidades conscientes e inconscientes en el ámbito de lo humano. Esa capacidad de proyectar por fuera de la conciencia y de autoreflexionar, nos permite tomar distancia frente a las cosas, de conocerlas, de aprenderlas como objetos y de transformar el mundo en un mundo cultural, que es como un cerebro externo a nosotros, que vive, se autoorganiza y permite generar diversas lecturas, interpretaciones, formulas, definiciones, construcciones, abriendo-cerrando, incluyendoexcluyendo el camino a múltiples métodos, lógicas, razones, técnicas y nociones de realidad. El ser humano es por naturaleza un ser cultural, personal, espiritual, excéntrico, abierto al mundo y al espacio, con dimensiones mensurables y no-mensurables. El ser humano es naturaleza aculturada y la naturaleza ha sido humanizada en procesos históricos que no siempre han sido muy adaptativos desde la perspectiva del acople cultura-ecosistema.

En general, en el desarrollo teórico de la antropología contemporánea, se pueden ubicar dos grandes tendencias que pueden pensarse como complementarias, pero que en el fondo son enfoques muy diferentes. Una primera tendencia, se visualiza claramente en los trabajos A. L Kroeber que entendió la cultura como una abstracción que puede ser captada en sus manifestaciones, dándole de esta manera mucha fuerza a los estudios sobre cultura material (1923, 1939, 1945). Una segunda tendencia, la podemos encontrar en los trabajos de C. Geertz $(1996,1990)$ referidos a entender la cultura como un sistema de contenidos simbólicos antes que materiales y que han abierto importantes frentes de trabajo en todo lo referido a los temas de la alteridad, la antropología de lo cercano, lo cotidiano, de la identificación de los diversos "mundos" existentes en el contexto del mundo globalizado y arrasado de esquemas totalizantes, 
dados por las imágenes que nos proyectan la multinacionales y los medios de comunicación.

Cabe subrayar que, ante la fuerza hegemónica de las ciencias naturales, la antropología debe siempre recordar los planos y dimensiones simbólicas e imaginarias en los procesos de configuración del territorio por parte de los sistemas culturales. Es decir, la escala temporal histórica tiene que hacer consciente, que el ser humano, incluso en la modernidad se encuentra viviendo a escalas cósmica e históricas cuya realidad es un mitologema y no un filosofema. La evidencia empírica de diversos trabajos monográficos en antropología estructura interpretativamente el argumento mitológico. Debe entenderse que el mito como narración "sagrada" de la realidad y de meta-realidades, tiene la fuerza para movilizar y codificar la conducta humana generando conductas (ritos) que establecen una conexión entre la visión de la realidad (cosmovisión) y el actuar en la realidad (ethos).

Ahora, como símbolo y expresión del mitologema mencionado, la crisis ambiental también es el reconocimiento de la pérdida de contenidos vitales en el plano simbólico. Las disecciones científicas han reducido la realidad de la natura-cultura a datos. En lo más profundo del origen de los problemas ambientales nos encontramos con una catástrofe metafísica que ha erosionado la figura del ser humano que encontramos en la filosofía occidental (Cárdenas, 2017; Yannaras, 2004, 2011,2012). Los motores dominantes de occidente nos hablan de una ciencia profana separada de lo sagrado, positiva y objetiva; esa ciencia se basa en los postulados de las ciencias naturales y acude a la historia como factor de explicación preponderante desde el esquema de linealidad; la ciencia occidental incluso en sus variantes profanas, se legitima con un fuerte sentido de las jerarquías que entran a dominar el acceso al conocimiento en base al mito del progreso (Cfr. Durand, 1998, 1981, 1968).

Estas posturas hacen parte de la antropología. La objetividad como fuerza que separa el mundo y como oficializadora de dualismos la encontramos en pensadores como Marvin Harris (1968). Para él, el objetivo de la antropología es entender la causalidad, las diferencias y las semejanzas existentes en los sistemas culturales. Como vemos ese es un enfoque muy retador, pero se inscribe en la tradición positivista de la ciencia occidental, que ha sido tan duramente criticado en los últimos treinta años (Pannikar, 1999; Prigogine, 1970,1977; Brown, 1988; Morin, 2000). Por fortuna, el pensador Claude Lévi Strauss (1958, 1962 1963,1968) desde el espacio teórico del estructuralismo, abrió una importante puerta alternativa para el estudio de las relaciones de los sistemas culturales con la base biofísica. Su aporte radica en haber explicitado los descubrimientos de una larga tradición de estudios antropológicos, que 
le permitieron a Lévi Strauss postular, especialmente en su obra El pensamiento salvaje (1962), que tanto la mente del ser humano primitivo como la del llamado civilizado trabajan desde las mismas estructuras clasificatorias; en el fondo tanto el mito, la religión como la ciencia tratan de sistematizar y ordenar la realidad desde esquemas totalizantes. En definitiva, el pensamiento es un producto social que depende de las instituciones sociales. Lévi Strauss ha formulado ese descubrimiento en las siguientes palabras:

"El hombre del neolítico o de la protohistoria es, pues, el heredero de una larga tradición científica; sin embargo, si el espíritu que lo inspiró a él, lo mismo que a todos sus antepasados, hubiese sido exactamente el mismo que el de los modernos, ¿̇cómo podríamos comprender que se haya detenido, y que varios milenios de estancamiento se intercalen, como un descansillo, entre la revolución neolítica y la ciencia contemporánea? La paradoja no admite más que una solución: la de que existen dos modos distintos de pensamiento científico, que tanto el uno como el otro son función, no de etapas desiguales de desarrollo del espíritu humano, sino de los dos niveles estratégicos en que la naturaleza se deja atacar por el conocimiento científico..." (1962: p. 33).

No se puede perder la memoria sobre una idea básica de la antropología: es fundamental entender que todos los hombres y todas las sociedades pueden sentirse que viven en un ambiente interdependiente propio y único (etnocentrismo), histórico-cultural, que genera estilos de vida particulares y cuyas instituciones son forjadoras de la subjetividad y esquemas cognitivos de los miembros de esa cultura. La idea de ambiente es una creación del biólogo Jacob von Uexküll (1926) y sirve para entender que los organismos viven en un "mundo perceptible" y "un mundo de efectos" que le es exclusivamente propio. Mi ambiente refiere una noción de realidad, mediatizada por un contexto, una experiencia, una práctica y un proceso no siempre consciente de autoreflexión y evaluación que es único, pero que además tiene que ser aprendido como proceso y actividad socialmente compartida. Como nos indica Erich Rothacker (1957: P. 141): en el ambiente del coleóptero hay solamente objetos coleoptéricos; en el ambiente de libélula, solamente objetos de libélula. En el ambiente humano cada persona y sistema cultural viven su realidad desde actos guiados por intereses y niveles de profundidad-proyección del mundo que no necesariamente corresponden a la lógica de vida existente en los sistemas biofísicos, ni a sus capacidades de carga. Estamos ante una paradoja y una situación muy frágil, riesgosa y peligrosa tanto para la biosfera como para el propio 
ser humano. Podemos sentir que hemos captado la realidad, ya sea desde la ciencia o la religión cuando en definitiva no es sino una aproximación parcial a la verdad, tal como lo afirmaba nuestro profesor español José Lorite Mena en su libro de antropología filosófica titulado El animal paradógico (1982). El mismo Rothacker nos recuerda como este esquema argumentativo implica que la realidad se arma en torno a un conjunto de diferencias que hacen que un mismo bosque sea un "monte" para el campesino, "un vivero" para el funcionario forestal, "un distrito de caza" para el cazador, "la sombra refrescante del bosque" para el excursionista, "la guarida" para el perseguido, y "el misterio de las copas de los árboles" o "el aroma embriagador de la resina" para el poeta (1957: p. 145).

Consecuentemente, el ambiente natural puede ser visto como un símbolo polivalente abierto a las interpretaciones de la ciencia experimental, pero también a la interpretación de los modelos cognitivos de los saberes y stocks culturales que han poblado la tierra, así como a las interpretaciones individuales de cada cual. Las anteriores ideas son las que desde mi propia condición espaciotemporal considero "exactas" para emprender la lectura sobre la relación ecosistema-cultura, especialmente en los tiempos del no lugar y de la aceleración de la historia en que vivimos (Auge, 1995, 1996). En este sentido, el conocimiento tradicional o pensamiento ancestral, uno de los campos más estudiados por la antropología, debe ser ampliamente valorado en el contexto de sus aportes para reencontrar el sentido de la tutela protectora sobre la naturaleza, sobre el hombre y la comunidad.

\section{Delimitación teórica de problemas no resueltos en la antropología:}

Es revelador recordar los grandes cambios ocurridos en términos de la concepción de la relación ecosistema-cultura en el espacio de la civilización occidental en los últimos doscientos o trescientos años. Dichos cambios han impactado con fuerza en la mayoría de las disciplinas científicas. En las filosofías de la edad moderna el ámbito natural se entendió como enfrentado a la cultura y viceversa. En el siglo XIX, las antropologías del período clásico prefirieron aislar to humano de lo puramente natural. En la actualidad, las graves perturbaciones ecológicas, nos obligan a mirar con mayor atención los vínculos de la relación ecosistema-cultura. En el nuevo contexto mundial, es clara la relación entre conservación de la biodiversidad y el papel que juega en ese proceso la diversidad cultural existente aún en el planeta. Por tanto, el conocimiento sobre otras culturas y sus formas de adaptación ecosistémica ha tomado un enorme valor en la actualidad (Moran, 1993; Odum, 1989). 
Muchas de las interpretaciones dadas por la antropología y referidas a la estrecha interrelación entre la cultura, la tecnología humana y la naturaleza del planeta se han nutrido de los avances ocurridos en los campos de la geología, la biología, y la paleoantropología. La ciencia occidental ha descubierto nuevas perspectivas. Por ejemplo, la etnociencia descubre conocimientos muy valiosos en los sistemas de conocimiento ecológico tradicional que ya vienen contribuyendo en la elaboración de importantes conceptos de conservación de la biodiversidad y en el propio fortalecimiento cultural que adelantan muchas comunidades aborígenes alrededor del mundo (WWF, 2000).

Por una parte, no existe unanimidad de enfoques ni de criterios para abordar el estudio de la relación entre el ecosistema y la cultura. Una de las causas para explicar las amplias libertades epistemológicas en los terrenos de la disciplina, puede explicarse en función de los orígenes filosóficos del viejo debate entre el idealismo y el materialismo. Otra dimensión explicativa descansa sobre la base de la misma complejidad de las huellas de lo humano en el territorio. Suele suceder que intelectuales y el público en general no familiarizado con los niveles de complejidad, con los campos de acción y de interés de la antropología, piensen que todavía ella no está viviendo plenamente un proceso de "ciencia normal" (Kuhn, 1989: pp. 55-93).2 El influjo de diversas corrientes filosóficas y de visiones de mundo en la antropología se evidencia en la gran heterogeneidad de las producciones académicas que abordan un mismo tema y que en muchos casos no tienen supuestos teóricos similares. Ese hecho es el que puede hacer pensar y dudar, - siguiendo a Kuhnsobre los resultados de la "actividad científica normal" de la disciplina.

Desde luego que las diversas posibilidades de interpretación, escuelas y la presencia de diversas antropologías culturales (política, económica, médica, ecológica, urbana), no quiere decir que no se hayan superado en el terreno teórico antiguos debates y que adicionalmente no se pueda entender esa polifonía interpretativa como una de las principales fortalezas de la disciplina. No debemos olvidar que el antropólogo se enfrenta con "partículas vivientes" mucho más complejas que los átomos, y con "organismos" que no se pueden reducir a dimensiones estrictamente biológicas. El mundo del caos, recientemente descubierto por la física, es un tema implícito y recurrente a to largo de la gran parte

\footnotetext{
2 Si bien el descubrimiento de la "revoluciones científicas" por T.S. Kuhn fue el embrión de una teoría muy influyente en la filosofía e historia de la ciencia, uno de los puntos más importantes se refiere al término de "ciencia normal", es decir, "una investigación basada firmemente en (...) realizaciones científicas pasadas, (...) que alguna comunidad científica particular reconoce, durante un cierto tiempo, como fundamento para su práctica posterior" (p. 33). Para Thomas Kuhn, el padre de los paradigmas, las ciencias sociales son "preparadigmáticas".
} 
de los trabajos etnográficos y etnológicos de los últimos cien años.

Por otra parte, todos los antropólogos socioculturales saben que la tarea de clasificación subyacente a la investigación implica entender que los pueblos, culturas y sociedades estudiadas tienen sus propias categorías de clasificación (hibridizadas, contaminadas, destruidas o civilizadas) de la realidad que deben de ser descubiertas, identificadas y traducidas por el antropólogo. A su vez el antropólogo en su lectura "etnográfica" de la realidad sabe que esas mismas categorías que estudia como "naturaleza", "tierra", "agua", "paisaje", "territorio", "energía", "sabiduría", etc. son categorías que tienen una definición diferente en su propia cultura y que además es la que normalmente se impone o se da por "natural". Las culturas humanas son una torre de babel y la tarea del antropólogo es descifrar y traducir los diversos códigos existentes y velar por establecer auténticos puentes de diálogo intercultural, desde la clara toma de conciencia de que la cultura dominante, de la cual él hace parte, en muchos casos en calidad de marginado y sin poder político alguno: el antropólogo más preparado sencillamente entiende la realidad desde los marcos totalitarios de su racionalidad, su ciencia, su técnica, su ética y en general desde la cosmovisión de raíces occidentales con sus ramificaciones de progreso y desarrollo unilineal.

Conforme a esto, el ser humano, precisamente por su condición de alteridad señera en la naturaleza, y como ser biosocial, necesita desarrollar permanentemente modelos, mentefactos, sociofactos y artefactos (ideas, organizaciones, tecnologías, herramientas) que le permitan clarificar su posición en el mundo, y la comprensión de dicho mundo o mundos, como también la forma de actuar en el planeta. En la base funcional más rudimentaria de la(s) cultura(s), están en un plano las necesidades de supervivencia de la especie, que se expresan en determinantes materiales, naturales, y las funciones biológicas propias de todo animal. Ese es el plano de las necesidades humanas, tema ampliamente abordado por la filosofía occidental y las ciencias humanas en general. En un segundo plano, se encuentran los determinantes metafísicos, religiosos y espirituales. Los determinantes materiales, referidos al hombre natural, hacen referencia a la necesidad de la alimentación, la salud, el vestido, la vivienda, el trabajo y la procreación. Esa sería la antropología funcional de Malinowsky (1982). Los determinantes espirituales y religiosos sellan de manera particular la forma en que el ser humano, como ser cultural, suple y resuelve sus necesidades materiales y sus funciones físicas.

El ser humano es un ser dispuesto y abierto al mundo de la alabanza, de la trascendencia, de la fiesta sagrada, de la intuición trascendente, y del rito de paso, con toda su belleza y violencia. Ésa es su condición 
diferencial y su lugar singular en la naturaleza. Condición que nos habla de la fiesta, de la mentira, del lenguaje y del mundo de lo religioso que viene acompañando al ser humano desde su misma génesis como humanidad. El ser humano genérico, a diferencia del hombre natural, actúa y se relaciona como ser social, interpretando estética y sensualmente el mundo desde lo físico y lo mental. En consecuencia, ambos planos son inherentes al ser humano y a los paisajes humanos. El hombre y sus sistemas culturales no se pueden despojar de las relaciones con la naturaleza biofísica. Es imposible, de hacerlo sería un simple animal, es más estaría muerto. Pero la llamada naturaleza biofísica es en el fondo un argumento simbólico que expresa topologías inmensamente variadas, ricas, y coloridas de paisajes mentales y materiales.

Se trata, en todo caso, de reconocer que el mundo humano es eminentemente cultural. El universo del ser humano se caracteriza por un dinamismo que va más allá del movimiento caótico que vienen descubriendo los físicos y matemáticos en relación con el mundo de lo orgánico e inorgánico, ya que está penetrado de símbolos, historicidad, intersubjetividad, estructuras de sentido, percepciones, conocimiento, representaciones, valores, experiencias, relaciones y pensamientos que se plasman en los espacios sociales y ambientales creados dialécticamente por el ser humano en un proceso de doble vía: el espacio social y ambiental lo construimos y ese espacio construido determina y construye al ser humano, generando experiencias de orden únicas e irrepetibles en la experiencia humana sobre la realidad. La cultura -como código arbitrario, no siempre adaptativo- establece y proporciona las pautas básicas para relacionarnos con el ambiente y condiciona nuestras representaciones del mundo en el marco de relaciones de sociales, estructuras de poder y dominación que afectan la realidad humana y nohumana. En palabras de Jesús Azcona (1994: P. 47): "El mundo intersubjetivo es un mundo en el que no solamente me comunico con los otros en un lenguaje común, sino que, además, lo que me comunico con los otros es social: es algo que existe, que está ya dado, creado e interpretado de antemano por generaciones de hombres que precedieron. Se trata de todo un conjunto de tipificaciones conductuales, de significaciones y de sentimientos que el individuo recibe como herencia social".

En todo caso, lo cierto es que la antropología es una ciencia en construcción, que básicamente, al igual que las otras ciencias sociales, ha estado en manos, en su variante occidental, de marcos teóricos que han condicionado jerárquicamente la disciplina a los postulados de las ciencias naturales (Brown, 1988: p. 222), que a su vez se han basado en las premisas de la física. Desgraciadamente, en las ciencias sociales y muy particularmente en la antropología, se tiene la tara histórica de pensar 
que los hallazgos de las ciencias duras —en este caso todo lo relacionado a los apasionantes descubrimientos referidos al entendimiento de sistemas complejos, caóticos y no lineales - son aplicables sine que non directamente al campo de lo social y cultural. Se olvida que muchas dimensiones de lo humano generan ordenes de realidad distintas, ya que lo sociocultural en muchos aspectos está mucho más allá del exclusivo dominio de las leyes de la física, la química y la biología. La antropología, como dice Heidegger está devastada en muchos aspectos, ya que nuestro propio reflejo nos conduce por los campos de lo incognoscible, y ante los cuales la ciencia positivista y reduccionista no puede introducirse. En consecuencia, vale la pena recordar, los postulados que se vienen manejando desde la formulación del principio antrópico, enunciados que nos recuerdan, desde el manejo de diversos factores de la física y la astronomía, que el universo entero existe como espacio para la vida y se orienta en función de posibilitar la existencia del ser humano. La más mínima modificación en los factores de densidad del cosmos, alterarían las posibilidades de generación de la vida y del surgimiento del género homo. El físico norteamericano, John Wheeler, interpreta muchos de los descubrimientos provenientes de la mecánica cuántica y la astrofísica, como evidencia para entender que las observaciones realizadas por el ser humano reflejan el diseño de un universo que se orienta para que el ser humano lo pueda pensar y vivir (1986: p. vii). Es imposible imaginarse un universo que contenga vida y en el cual, cualquiera de las constantes de la física fuera levemente diferente a las actuales. Ya el azar dejó de ser una explicación plausible y si Darwin viviera, él sería el primero en reconocerlo ${ }^{3}$. En general estas afirmaciones nos permiten recordar el carácter no lineal que debe caracterizar el desarrollo del discurso y de la investigación en el campo de las ciencias sociales. Como nos dice Brown, resulta que no podemos reducir la cultura a la biología, noción que es compartida incluso por muchos biólogos (en Brown, op. cit: p. 222).

Ahora bien, no podemos tampoco desconocer las relaciones entre la cultura y la biología, ya que la cultura se puede entender a partir de la dinámica de un proceso evolutivo que a grandes rasgos nos habla de la interacción del viviente con su medio, su reproducción y el manejo de información. Estos despliegues del fenómeno vifal se expresan culturalmente como técnica, manejo de conceptos, símbolos, proyectos, creaciones individuales y colectivas de las pautas de conducta. En ese

\footnotetext{
${ }^{3}$ En una carta de Darwin a Asa Gray, del 22 de mayo de 1860, expresa la relación causal de su teoría evolutiva con la ley del azar: "Me inclino a considerar todas las cosas como resultado de leyes deliberadas en las que se deja que los detalles buenos o malos, los determine lo que podríamos llamar el azar. Y no es que esta solución me satisfaga en absoluto. Estoy íntimamente convencido de que la totalidad la cuestión es demasiado profunda para la inteligencia humana" (Darwin, 1977: pp. 350-351).
} 
orden de ideas, París diferencia lo que él denomina los paradigmas de la técnica animal y la técnica humana. Y la técnica se constituye en la entrada al laberinto para establecer las relaciones entre la biología y la cultura, como también sus perfiles diferenciadores. El examen de la técnica nos revela nuestra cercanía al mundo de lo biológico, pero igualmente nos proyecta los rasgos diferenciadores del mundo humano. En términos generales, la investigación biológica, zoológica y etológica vienen descubriendo en distintas formas de vida (insectos, chimpancés, bacterias) lenguajes, gramáticas y procesos de aprendizaje que habíamos pensado que eran exclusivos del ser humano. Ciertamente el dominio técnico se da en el reino de la vida, sin embargo, la técnica humana se caracteriza por determinadas "novedades radicales" que se pueden simbolizar desde los siguientes conceptos: pluralismo, instrumentalidad extrasomática, relaciones mitopoéticas, e inventividad.

Curiosamente, los desarrollos recientes de la física y la biología evolutiva nos llaman la atención en el sentido de indicarnos que no nos preocupemos tanto por aspirar a los modelos decimonónicos, positivistas, y newtonianos de la ciencia tradicional -con toda su capacidad predictiva-. Más bien, debemos reconocer que la misma complejidad de los sistemas socioculturales nos obligan a mirar a las culturas, como normalmente lo hemos hecho, pero sin avergonzarnos, como entes integrados y abiertos, salpicados de interrelaciones sistémicas y dinámicas entre sus partes, y en donde la comparación y el análisis transcultural es importante como fuente de comprensión no predictiva.

En el mundo contemporáneo, la antropología -a pesar de los límites que ya se han señalado- juega un papel fundamental en ayudarle a comprender al ser humano la dinámica sociocultural y los graves problemas que enfrenta la sociedad humana en su conjunto. Necesitamos comprender para transformar la realidad. Y la antropología representa la mejor fuente de teoría social para aplicarla en ese esfuerzo. Para Tom Abel (1998: p. 3), la antropología, como ciencia social, tiene: "la profundidad temporal, los datos comparativos y el interés y sensibilidad por el pensamiento evolutivo-ecológico-económico que es necesario".

Tenemos que hacer de las disciplinas ambientales, ciencias basadas en la construcción de mecanismos justos de interacción social y natural dirigidos hacia la generación de equilibrios dinámicos y adaptativos que se traduzcan en procesos de apertura al mundo y en la generación de riqueza espiritual y material. Consecuentemente es clave pensar, y volver a los planteamientos iniciales de la economía política, los que se centraban sobre la generación y la distribución de la riqueza socialmente construida; pero enriquecer esa visión económica y política desde marcos que respondan al diseño cultural-ecológico, que entiende que el 
desarrollo sostenible es en el fondo una narrativa bioregional basada en las condiciones concretas de ubicación espacio-temporal de los individuos, las familias, las poblaciones y los ecosistemas. Además, tenemos que ser muy cuidadosos, para no caer de nuevo en la trampa de las visiones neofuncionalistas que pueden estar detrás de las concepciones sistémicas, que hoy orientan el trabajo de investigación de diversas disciplinas científicas. Como nos diría Ikenna Nzimiro, antropólogo africano, "la antropología del futuro es la antropología de la liberación" (1988: p. 233). Es decir, la antropología, no puede olvidar categorías claves para la comprensión de los marcos conflictivos que se dan al interior de la sociedad capitalista y que repercuten en la configuración humana sobre el territorio, tales como la noción de clase, discriminación racial, genero, etnia. En el fondo, la problemática ambiental es un producto histórico complejo que da cuenta de las relaciones contradictorias de poder entre el mundo occidental y los países del llamado Tercer Mundo. Como es claro, las orientaciones marxistas tienen el potencial de brindarnos pautas para la práctica social y para la superación de los marcos funcionalistas que entienden las relaciones culturales como expresión de sistemas en equilibrio. Por el contrario, la dialéctica marxista, revela las contradicciones internas de cualquier sociedad, y en ese sentido la visión marxista de la historia puede esclarecer la naturaleza de los problemas ambientales que tienen una causalidad eminentemente sociocultural. Así pues, la conexión entre los social y lo natural puede superar el exclusivo eje ecológico o tecnológico que caracteriza muchas de las aproximaciones a la cuestión ambiental.

Desgraciadamente, las distancias y diferencias impuestas por los sistemas estatales, que reproducen sistemas operativos y modelos cognitivos basados en el egoísmo, la exclusión económica, social, política, y productiva, y que se expresan en el paisaje humano en una compleja red de estratificaciones sociales, viene marginando a muchos habitantes del planeta al acceso a los bienes de uso más elementales, y esa condición económica es una de las causas de la crisis ecológica que vivimos y que venimos provocando.

En general, algunos de los modelos socioeconómicos y biológicos, que están en boga, pueden llegar a ser reduccionistas, ya que generalmente solo integran variables utilitaristas inspirados en la supuesta existencia universal de un homo economicus que solo busca maximizar su ganancia o se basan exclusivamente en el poder explicativo de las dimensiones emergentes de la realidad, captadas por la utilización de los sistemas de información georeferenciados, entrando a modelar a partir de pocas variables incluso de tipo biofísico (por ejemplo sencillamente se ignoran los cambios climáticos en periodos cortos o largos de tiempo), y de esa forma se dejan de lado las "fuerzas invisibles" tanto en lo social como en 
lo ecológico que son tan reales como las condiciones emergentes que vemos como producto de la tabulación de encuestas, juegos o descripción de los atributos emergentes del paisaje dados por la fotografías aéreas o imágenes de satélite (cobertura y geoforma). Sencillamente recordemos que la antropología económica (Malinowsky, 1982; Godelier, 1976) al igual que la sociología (Weber, 1974), desde la década de los años treinta, claramente demostraron que los sistemas económicos de muchas culturas no funcionan desde la lógica mercantil, la competencia o desde el criterio de la mano invisible con el que se ha pretendido entender el funcionamiento de las economías de mercado occidental. Cuando aplicamos esas "leyes" y supuestos (que son incluso muy débiles para entender nuestra propia sociedad capitalista) a otras culturas y generamos modelos sobre la base de las variables que fundamentan esas leyes, de entrada, toda la simulación y los resultados del modelo no son más que una quimera idealista, que puede "inconscientemente" justificar en base a estructuras de poder todo el proceso de pillaje que viene impulsando la racionalidad conquistadora del mundo capitalista.

\section{Concluyendo}

La antropología es una ciencia que ha estado enfrentada permanentemente a la crisis ambiental generada en los últimos doscientos años por el desarrollo y consolidación del capitalismo. Su contacto de primera mano con los procesos de etnocidio, genocidio y ecocidio que ha ejercido la sociedad dominante entre los marginados herederos de la biodiversidad, le exigen clarificar nociones de realidad que han enriquecido el análisis de otras disciplinas, tanto de las ciencias sociales como de las ciencias naturales. Igualmente, la crisis ambiental, cuyo fondo moral y cultural es evidente para la antropología, le ha permitido a los sectores intelectuales occidentales el aproximarse a la realidad del otro -por lo menos idealmente- desde un marco de tolerancia, respeto y admiración. La gran aventura investigativa de la antropología tiene que pensarse desde horizontes epistemológicos. Se requieren apoyos semióticos y lógicos que le permitan a sus científicos y estudiantes comprenderla importancia de la más importante y compleja de las ciencias sociales. Para ello ideas de cuño incluso filosófico se hacen indispensables en el proceso de clarificación epistemológico, gnoseológico y ontológico de la disciplina.

Conforme a lo anterior, conviene notar que somos seres que vivimos en un mundo de significados construidos, intuidos, autoreflexionados e impuestos desde un código arbitrario llamado cultura, cuyo culto refiere incluso la posibilidad y realidad sentida por muchos pueblos a todo lo 
largo de la historia que aceptan sin problemas, a diferencia del hombre de la modernidad, que la historia también la construyen los demiurgos, los dioses o simplemente Dios. Por supuesto que estamos sujetos a las leyes del mundo físico, pero condicionados fuertemente por nuestros universos simbólicos que tienen la fuerza de tener vida propia. La humanidad es una especie que vive y que sólo puede vivir en términos de significados. El mundo en el que vivimos los seres humanos no está solamente constituido por fuerzas biológicas, geológicas, tectónicas o climáticas. El mundo humano interpreta y construye la realidad natural y social desde su propio mundo cultural y esquema de significados. Y como notó Charles Sanders Peirce (2012) el hombre sólo piensa en signos.

Como seres animados pertenecientes al orden de los primates, género homo, manejando una visión estereoscópica, y una habilidad prensil en nuestras manos, interpretamos y manipulamos la realidad de los árboles, las piedras y el océano fundamentalmente desde un plano simbólico que determina y condiciona en cada cultura las reglas, taxonomías, cosmologías, instituciones y valores del universo material que captamos a través de los sentidos. El lenguaje es propio y exclusivo de la especie; se reconoce la existencia de sistemas de comunicación y proto-lenguajes en otros seres vivos, pero la utilización del símbolo y del signo sigue siendo un atributo exclusivo del ser humano. El lenguaje, junto con el trabajo manual e intelectual, es una de las "esencias" del ser humano, con el que construimos el mundo ya sea en términos de calidad o cantidad, de bueno o malo; o desde la utilización de sistemas lógicos abstractos referidos al buen gobierno, los valores del honor, la reciprocidad, la economía, las matemáticas o los imaginarios referidos a los dioses, espíritus o ángeles. Muchas de esas dimensiones las entendemos como reales, cuando en repetidas ocasiones han sido construcciones sociales e individuales que estructuran el universo del ser humano, siendo tan sólo nociones de realidad. El ser humano puede mentir, puede auto engañarse, puede sacrificarse y puede matar por otros. Esa condición tiene que ver con nuestras posibilidades creativas y destructivas, júnicas en el reino de la vida!

En concreto, el universo humano está sujeto a las leyes del mundo natural; pero es inmensamente más rico, problemático, complejo, ambiguo y dinámico. Cada sociedad humana ha construido una cultura única a lo largo de la historia. Como ha demostrado la arqueología, al interior de un ecosistema similar y en los mismos tiempos y registros históricos han existido culturas muy disímiles que han planteado un entendimiento especial y único con los árboles, las rocas y con la vida que los rodea, así como con lo visible e invisible. Los grupos humanos han transformado no solamente sus sistemas sociales, sino adicionalmente los ecosistemas, que vienen sufriendo acelerados cambios emergentes, funcionales y estructurales, 
impulsados especialmente con el desarrollo de la agricultura y la revolución neolítica hace unos 7,000 años.

No se puede negar que nuestra herencia occidental nos ha hecho cómplices y culpables de las grandes aventuras y procesos de devastación, muerte y graves perturbaciones engendradas a miles de culturas no occidentales. Es por eso que la autoconciencia antropológica en su historia descriptiva de los cargos cults, también deberá recordar sus cargos culposos como ciencia cómplice de las aventuras colonialistas nacidas desde el primer mundo. El discurso antropológico paradójicamente se aprobó con base en la filosofía de Hegel, Descartes, y Kant, y desarrolló un proyecto "civilizatorio" de "apertura al mundo" (Gehlen, 1993), que se autoproclamó como la única verdad y senda a recorrer por todos los pueblos y naciones. Como se entiende, la globalización no es un hecho reciente, la feroz capa de la historia occidental ha querido asfixiarnos a todos. La genialidad del paganismo ha tenido que ser defendida especialmente por los antropólogos, y recientemente por teólogos "iluminados" como Raimon Pannikar (1999) y teólogos "herejes" como Leonardo Boff. La aventura de la conciencia occidental, como nos recuerda Jean Monod, está dialécticamente relacionada y supone "la negación del otro y nuestra expansión en su territorio material y mental, es decir, la sustitución de sus leyes por las nuestras, civiles y mentales" (en: Jaulin, 1976:345).

Lastimosamente tenemos que reconocer, que la versión secular del misionero ha estado representada en muchas oportunidades por el aprendiz de antropólogo, que incluso sin quererlo ha sido el portaestandarte del saber absoluto y enciclopedista de la ciencia occidental y de su idea de progreso y desarrollo. Nos hemos disfrazado de aliados de los llamados grupos autóctonos y tenemos que reconocer que en muy numerosas ocasiones hemos sido pésimos aliados. En muchas ocasiones hemos estado más preocupados por las fuentes de financiación y las publicaciones de nuestros universos ideales referidos al indio o el primitivo, que a un verdadero compromiso con los grupos que nos han abierto las puertas de sus universos culturales, ecológicos, sus sentimientos individuales, comunitarios y personales. Sin embargo, desafortunadamente tenemos que reconocer que el proceso referido ha sido de doble vía, ya que los grupos indígenas en su contacto con los centros de aprovisionamiento del ser humano blanco y su cultura han mordido "con demasiada fuerza el anzuelo tecnológico" (Monod,1975:55). Sencillamente tenemos que reconocer que muchas comunidades indígenas participan activamente y desde hace muchos años de la economía de mercado. El "magnetismo tecnológico" con toda su parafernalia material e ideológica contaminó a muchos sectores del mundo indígena y los llenó con los códigos mentales y materiales de 
occidente. De todas maneras, sus relaciones con el ambiente biofísico y con el cosmos en general, todavía nos pueden enseñar multitud de saberes, valores, principios, prácticas, cosmovisiones y discursividades territoriales y culturales necesarias para la supervivencia de la humanidad.

\section{BIBLIOGRAFÍA}

Abel, T. (1998). Complex Adaptive Systems, Evolutionism, and Ecology within Anthropology: Interdisciplinary Research for Understanding Cultural and Ecological Dynamics. Publicado en: The Georgia Journal of Ecological Anthropology. Vol. 2.

Augé, M. (1996). Los "no lugares " Espacios del anonimato. Una antropología de la sobremodernidad. Barcelona: Editorial Gedisa.

Auge, M. (1995). Hacía una antropología de los mundos contemporáneos. Editorial Barcelona: Gedisa.

Azcona, J. (1994). Para comprender la antropología. La historia. Navarra: Editorial Verbo Divino.

Bateson, G. (1993). Una unidad sagrada: pasos ulteriores hacia una ecología de la mente. Barcelona: Gedisa.

Brown, C.W, (1988). La renovación de la investigación interdisciplinaria y la antropología de la década de los noventa, en Revista Internacional de Ciencias sociales, no. 116, Unesco.

Cárdenas-Támara, F. (2017). La raíz ontológica de la crisis ambiental. El magisterio de su santidad Bartolomé. Theologica Xaveriana, vol. 67, núm. 183, enero-junio, Bogotá: Pontificia Universidad Javeriana. Pp. 35-61.

Cárdenas- Tamara, F. (2016). El signo paisaje cultural desde los horizontes de la antropología semiótica AIBR. Revista de Antropología Iberoamericana, vol.11, núm. 1, enero-abril. Madrid: AlBR. Pp. 106-129.

Castañeda, C. (1976). Relatos de Poder. México: Fondo de Cultura Económica.

Castañeda, C. (1984). El Don del Águila. México: Editorial Edivisión, Durand, G. (1981). Las Estructuras Antropológicas de lo imaginario. Madrid: Ed, Taurus. 
Durand, G. (1968). La imaginación simbólica. Buenos Aires: Amorrortu editores.

Durand, G. (1999). Ciencia del hombre y tradición. Barcelona: PaidósOrientalia.

Geertz, C. (1996). Los usos de la diversidad. Barcelona: Paidós.

Geertz, C. (1990). La Interpretación de las culturas. Barcelona: Gedisa editorial.

Gehlen. A. (1993). Antropología filosófica: del encuentro y descubrimiento del hombre por sí mismo. Buenos Aires: Paidós.

Godelier, M. (1976). Antropología y economía. Barcelona: Anagrama. Harris, M. (1968). El Desarrollo de la teoría antropológica. Madrid: Siglo Veintiuno.

Jaulin, R. (1976). La paz blanca: introducción al etnocidio. Buenos Aires: Tiempo Contemporáneo.

Kroeber, A. (1923). Race, Language, Culture, Psychology, Prehistory. California: .Harcourt, Brace World, Inc.

Kroeber, A. (1939). Cultural and natural areas of native north America. Berkeley: University of California.

Kroeber, A. (1945). Antropología General., México: Fondo de Cultura Económica.

Kuhn, T. (1989). ¿¿Qué son las revoluciones científicas? Barcelona: Paidós.

Lévi-Strauss, C. (1958). Antropologie structurale. París: Plon.

Lévi-Strauss, C. (1962). El pensamiento salvaje. México: Fondo de Cultura económica.

Lévi-Strauss, C. (1963). Totemism. Boston: Beacon Press

Lévi-Strauss, C. (1968). The Elementary Structures of Kinships. Boston: Beacon Press

Llobera, Jose I. (1979). Antropología Política. Barcelona: Ed, Anagrama. Lorite, Mena J. (1982). El Animal Paradójico. Madrid; Editorial Alianza. Malinowsky, B. (1982). Magia, ciencia, religión. Barcelona: .Ed. Ariel Moran, E. (1993). The ecosystem approach in Anthropology. University of Michigan Press.

Monod, J. (1975). Un rico caníbal. México: Ed. Siglo XXI. 
Morin, E. (2000). Los siete saberes necesarios para la educación del futuro, Orientaciones Universitarias, vol. 28. Bogotá: Pontificia Universidad Javeriana.

Nzimiro, I. (1988). Antropología, en: Revista Internacional de Ciencias sociales, no. 116, Unesco.

Odum, E. (1989). Ecology and our endangered life support systems. Stanford: Sinaver.

Pannenberg, W. (1993). Antropología en perspectiva teológica. Salamanca: Ediciones Sígueme.

Pannikar, R. (1999). La intuición cosmoteándrica. Barcelona: Editorial Trotta.

Peirce, C. (2012). Obra filosófica reunida. Volumen II. (1893-1913). México: Fondo de Cultura Económica.

Prigogine, I. (1977). Physics and Metaphisics. Advances in biological and medical Physics, vol.16.

Prigogine, I. (1984). The rediscovery of time, Zygon, vol.19, núm 4, December.

Rothacker, E. (1957). Problemas de antropología cultural. México. Fondo de Cultura económica.

Tylor, E. (1920). Primitive culture. London: John Murray.

Uexküll, J. J. (1926). Theoretical Biology. New York: Harcourt, Brace \& Co.

Weber, M. (1974). Historia Económica general. México: Fondo de Cultura Económica.

Wheeler, J. (1986). The Anthropic Cosmological Principle. Oxford: Clarendon Press.

World Wild Fund. (2000). Indigenous and traditional peoples of the world and Ecoregion Conservation. Switzerland: Terralingua.

Yannaras, C. (2004). Postmodern Metaphysics. Brookline (MA): Holy Cross Orthodox Press.

Press.

(2011). Relational Ontology. Brookline (MA):-Holy Cross Orthodox

. (2012). The Meaning of Reality. Essays on Existence and Communion, Eros and History. Los Angeles (CA): Sebastian Press. 